\title{
GIDDENS E BAUMAN: AS CONFIGURAÇÕES INSTITUCIONAIS NA CONTEMPORANEIDADE
}

\author{
GIDDENS AND BAUMAN: THE INSTITUTIONAL CONFIGURATIONS IN THE \\ CONTEMPORANEITY
}

\author{
Wallace Cabral RIBEIRO ${ }^{1}$
}

RESUMO: O estudo em tela tem por objetivo apresentar uma breve discussão acerca das interpretações sociológicas de Anthony Giddens e Zygmunt Bauman (1925-2017) no que tange à modernidade. Os autores divergem a respeito das consequências da modernidade nas interações humanas. Para Giddens, a "modernidade avançada" trouxe autonomia para os indivíduos; para Bauman, a "modernidade líquida" trouxe individualismo e esfriamento nas relações interpessoais. O presente texto discorrerá sobre alguns elementos teóricos e metodológicos mobilizados por cada autor para caracterizar as configurações institucionais na contemporaneidade.

PALAVRAS-CHAVE: Giddens. Bauman. Modernidade. Modernidade avançada. Modernidade líquida.

ABSTRACT: The study on screen aims to present a brief discussion about the sociological interpretations of Giddens and Bauman regarding modernity. The authors differ in regard to the consequences of modernity in human interactions, for Giddens advanced modernity brought autonomy to individuals; for Bauman, liquidi modernity brought individualism and cooling in interpersonal relationships. The present text will present some theoretical and methodological elements mobilized by each author to characterize the institutional configurations in the contemporaneity.

KEYWORDS: Giddens. Bauman. Modernity. Advanced modernity. Liquidi modernity.

\section{Introdução}

"Tudo o que era sólido se desmancha no ar, tudo o que era sagrado é profanado" (MARX; ENGELS, 2010, p. 14). Esse trecho pertence ao célebre Manifesto do Partido Comunista de 1848, e se constitui como uma das caracterizações de Marx e Engels acerca da sociedade de modo de produção capitalista. A burguesia não pode existir sem transformar constantemente os instrumentos de produção, as relações de produção e, por conseguinte, todas as relações sociais. Esse movimento ininterrupto gera insegurança e instabilidade, e

${ }^{1}$ Universidade Federal Fluminense (Uff), Niterói - RJ - Brasil. Graduando em Sociologia, editor da Revista Ensaios e membro do Núcleo de Estudos Cidadania Trabalho e Arte (NECTAR-UFF) e do Núcleo de Estudos Friedrich Engels (NEFE). E-mail: cabralwallaceribeiro@yahoo.com.br. 
essas peculiaridades diferenciam a era do capital de todas as outras épocas (MARX; ENGELS, 2010). Para Marshall Berman (1986, p. 117), o Manifesto Comunista é uma tentativa pertinente de "apreender uma experiência peculiarmente moderna". Nesse sentido, Berman (1986, p. 125) entende que Karl Marx é "um dos primeiros e grandes modernistas."2

Como Marx e Engels, os sociólogos Anthony Giddens e Zygmunt Bauman produziram, ao longo de algumas décadas, um arsenal teórico que também problematiza a respeito do fenômeno da modernidade. Giddens apresenta a ideia de "reflexividade", "política-vida", "sistemas de especializados" e "democratização das emoções" para discutir sobre a renovação das práticas e instituições sociais na "modernidade avançada". Bauman trabalha com os conceitos de "liquefação" e "desengajamento" para se referir ao esfriamento das relações humanas na "modernidade líquida". O universo categorial desenvolvido por estes dois autores deixa suas marcas indeléveis no pensamento sociológico. Giddens e Bauman são referências teóricas nos debates sobre política, economia, cultura, globalização, relações humanas, entre outros temas pertinentes ao campo da modernidade. O presente texto tem como proposta fomentar uma discussão sobre as caracterizações de Giddens e Bauman acerca das configurações institucionais na contemporaneidade.

\section{Anthony Giddens e a "modernidade avançada"}

Giddens atua intelectualmente no debate sobre a modernidade, com ponderações sobre as instituições sociais, o trabalho, as novas dinâmicas de tempo e espaço, a globalização, as relações humanas etc. Esse teórico apresenta de forma sucinta uma definição sobre modernidade ao afirmar que este fenômeno social "[...] refere-se a estilo, costume de vida ou organização social que emergiram na Europa a partir do século XVII e que ulteriormente se tornaram mais ou menos mundiais em sua influência." (GIDDENS, 1991, p. 11).

Giddens (2002) compreende que a modernidade pode ser entendida equivalente ao mundo industrializado, mas alerta que a industrialização não é o único fenômeno característico da modernidade. Este sociólogo rejeita a concepção de que a sociedade atravessa um período de pós modernidade. Para ele, “[...] estamos alcançando um período em que as consequências da modernidade estão se tornando mais radicalizadas e universalizadas do que antes." (GIDDENS, 1991, p. 13).

2 Apesar do Manifesto do Partido Comunista ser de autoria de Marx e Engels, Berman se refere apenas a Marx como "um dos primeiros e grandes modernistas". 
Em sua obra Modernidade e Identidade Giddens (2002, p. 22) identifica a existência de três elementos (ou conjunto de elementos), que ajudam a compreender o "caráter peculiarmente dinâmico da vida social moderna". São eles:

- Separação de tempo e espaço;

- Mecanismos de desencaixe;

- Reflexividade institucional.

Em relação à reorganização do tempo e do espaço na modernidade, o sociólogo britânico faz a seguinte observação "[...] a invenção do relógio mecânico e sua difusão entre virtualmente todos os membros da população (um fenômeno que data em seus primórdios do final do século XVIII) foram de significação-chave na separação entre o tempo e o espaço." (GIDDENS, 1991, p. 26).

A apreensão do mundo por meio da cartografia e pelos cronômetros trouxe uma nova ideia de objetividade e de precisão na representação espacial e temporal, isso se deu pela introdução dos princípios matemáticos na produção desse tipo de conhecimento, contribuindo para o aumento da racionalização, em detrimento da "sabedoria infinita da divindade" (HARVEY, 1989, p. 223).

Os instrumentos sofisticados de mensuração do tempo e do espaço juntamente com o "advento da modernidade" arrancaram o "espaço do tempo fomentando relações entre outros ‘ausentes', localmente distantes” (GIDDENS, 1991, p. 27).

A vida social moderna introduziu uma nova forma de organização do tempo e do espaço, como a uniformização dos calendários em escala mundial, a utilização de marcadores de tempo em diversas regiões e a adoção de mapas universais (GIDDENS, 1991). Esses fatos viabilizaram, em certa medida, a "expansão dos mecanismos de desencaixe" (GIDDENS, 2002, p. 10), ou seja, em "mecanismos que descolam as relações sociais de seus lugares específicos, recombinado-as através de grandes distâncias no tempo e no espaço" (GIDDENS, 2002, p. 10). Giddens se refere a dois mecanismos de desencaixe, as "fichas simbólicas", que são “[...] meios de troca que tem valor padronizado e são assim intercambiáveis numa variedade determinada de contextos." (GIDDENS, 2002, p. 222); e "sistemas especializados" que se refere a "[...] sistemas de conhecimento especializado, de qualquer tipo, dependentes de regras de procedimentos transferíveis de indivíduo a indivíduo." (GIDDENS, 2002, p. 223). Os dois tipos de desencaixe necessitam de "confiança", que é definida por Giddens 
como "[...] a crença em pessoas ou sistemas abstratos, conferida com base em um 'ato de fé' que põe entre parênteses a ignorância ou a falta de informação.” (GIDDENS, 2002, p.221).

Frente às ameaças ao desmantelamento das instituições provocado pela própria dinâmica da modernidade radicalizada, Giddens acredita que os "sistemas especializados" possuem um papel fundamental na manutenção das instituições (ou não desmantelamento), pois os "[...] os sistemas peritos condensam a fé no conhecimento e tranquilizam as pessoas pela competência e a eficácia demonstradas em estatísticas, consolidando referências e benefícios." (FRIDMAN, 2000, p. 07). Os sistemas especializados no cotidiano se movimentam no sentido de buscar o aperfeiçoamento para desenvolver qualitativamente a própria capacidade de equacionar os problemas (GIDDENS, 2002).

A "reflexividade institucional" é um conceito que se refere à submissão que "[...] as práticas sociais são constantemente examinadas e reformadas à luz de informação renovada sobre as próprias práticas, alterando assim constitutivamente seu caráter." (GIDDENS, 1991, p. 45). Um exemplo ilustrativo da reflexividade institucional apresentado por Giddens diz respeito à produção do conhecimento científico, que, metodologicamente, está sempre aberta a ser questionada, podendo ser revisada ou completamente descartada "à luz de novas ideias ou descobertas" (GIDDENS, 2002, p.26).

Outro exemplo paradigmático de reflexividade institucional são as discussões que ocorriam na cidade de Nova York na década de 1970 sobre as relações de gênero na sociedade, conforme abordadas por Wendy Goldman no prefácio à primeira edição brasileira de sua obra Mulher, Estado e Revolução.

[...] muitos grupos radicais debatiam como deveriam ser as 'novas relações' entre homens e mulheres. Como deveriam viver as pessoas que estão comprometidas com as mudanças sociais? Como poderíamos colocar em prática valores que desejamos ver em uma nova sociedade? (GOLDMAN, 2014, p. 10).

Essas questões refletiam sobre as práticas sociais das instituições do casamento, da família, da questão de gênero, da monogamia, da violência sexual, das hierarquias nas relações conjugais, dos valores morais, da moral sexual etc. Esses debates estavam em pauta no espírito de época (Zeitgeist) das décadas de 1960 e 1970, e são esmiuçados por Giddens em "A Transformação da Intimidade".

Para Giddens, a reflexividade fomenta nos relacionamentos íntimos a construção da confiança, possibilitando a "democratização das emoções". O conceito de "relacionamento puro" diz respeito aos relacionamentos íntimos auto referenciados, ou seja, a manutenção dos 
relacionamentos íntimos dependerá do alcance de satisfação individual de cada parceiro. Segundo Fridman (2014, p. 248), “o relacionamento puro traz o princípio da suspensão das hierarquias", não necessariamente em sua totalidade, mas:

O relacionamento puro traz, em suas condições básicas, a proibição da violência, a negociação de um 'contrato móvel' (e, portanto, passível de desistência de uma das partes segundo o padrão da autonomia) e o compromisso segundo as necessidades e o grau de satisfação de cada parceiro. (FRIDMAN, 2014, p. 248).

Giddens trabalha o conceito de política emancipatória, que se refere à busca pela liberdade e pela ruptura de algemas que limitam os indivíduos. Significa ter uma conduta de vida de luta contra a exploração e opressão emitidas por pessoas, grupos ou instituições. A política emancipatória luta pela destituição de poderes ilegítimos (GIDDENS, 2002) e, segundo Fridman (2014, p. 250), "expande a política da vida”.

A política-vida está relacionada às questões contestatórias desenvolvidas na reflexividade do eu, política de autorrealização e de adoção de um "estilo de vida", contextualizado na dialética do "local e do global" (GIDDENS, 2002). A política-vida corresponde a “[...] certo nível de autonomia de ação [...] ela é uma política de escolha [...], que num nível individual e coletivo, alterou radicalmente os parâmetros existenciais da atividade social." Simplificando, "a política-vida é a política do estilo de vida" (GIDDENS, 2002, p. 197), na qual os sujeitos “desenvolve uma ética relativa à pergunta 'como devemos viver?" (GIDDENS, 2002, p. 198), ou "quem eu quero ser?" A reflexividade do eu retroalimenta essas indagações de emancipação e auto-identidade.

O surgimento da política-vida, afirmei, resulta da centralidade do projeto reflexivo do eu na modernidade tardia [...]. A capacidade de adotar estilos de vida livremente escolhidos, benefício fundamental gerado por uma ordem pós-tradicional, está em tensão não só com os obstáculos à emancipação, mas também como uma variedade de dilemas morais. (GIDDENS, 2002, p. 212)

O conceito de política-vida em Giddens dialoga com o conceito de estética da existência em Foucault. Giddens compreende que as pesquisas de Foucault revelam que nas "sociedades de controle" os corpos estão sujeitados de tal forma que não viabiliza o surgimento de sujeitos críticos e reflexivos capazes de promover sua auto-emancipação e subversão do poder, pois segundo Giddens, a visão de Foucault sobre "corpo deixa muito a desejar. Ele não consegue analisar a relação entre o corpo e a agência" (GIDDENS, 2002, 58). 
A pesar das critica de Giddens a Foucault no que tange as relações de poder, a estética da existência confere aos sujeitos a "[...] possibilidade de se inventar novas formas de subjetividade ou novos estilos de vida, recusando o tipo de individualidade que nos foi imposto por vários anos." (GOMES; ALMEIDA; VAZ, 2009, p. 311). A estética da existência possibilita o sujeito interrogar a si mesmo, podendo adotar certos "estilos de vida" que se constituem como resistência as formas de assujeitamentos e de subjetivação dos poderes hegemônicos e de não aceitar "como verdadeiro o que uma autoridade sustenta ser verdadeiro" (FOUCAULT, 1999, p. 3).

A modernidade avançada nas últimas quatro décadas vivenciou dois eventos importantes que produziram profundas mudanças na sociabilidade. Uma foi na década de 1980, o neoliberalismo encabeçado pelos os Estados unidos da América de Ronald Reagan e pela Inglaterra da "dama de ferro" (Margaret Thatcher), que conjuntamente implementaram políticas de "liberação dos mercados", adotadas posteriormente em diversos países (inclusive no Brasil, na década de 1990, iniciado pelos governos presidenciais de Fernando Collor de Mello e Itamar Franco e também durante os dois mandatos de Fernando Henrique Cardoso). O neoliberalismo encampou com o modelo de Estado de bem estar social (welfare state). Para o programa neoliberal, Giddens propôs uma reflexão profunda sobre as formas de atuação política da social democracia, trazendo a tona a ideia de "terceira via" como alternativa política, que, segundo este autor possibilitaria a sobrevivência da social democracia através de sua adaptação aos novos tempos, surgindo uma "esquerda modernizadora" ou uma "social democracia modernizadora" (GIDDENS, 2001).

O segundo evento histórico foi o crollo do capitalismo de Estado do bloco político econômico militar soviético, e das ditaduras militares nos países latinos americanos. Estes acontecimentos abriram a largada da corrida da "democratização das democracias". Os países, antes submetidos à esfera de influencia da União Soviética e das ditaduras militares latino americanas, passaram a experimentar a implementação de modelos políticos democráticos. Para Giddens, a globalização estaria nos bastidores dessas mudanças. Segundo ele, a globalização é uma articulação "dialética do local e do global”, está relacionada à “[...] interseção entre presença e ausência, ao entrelaçamento de eventos e relações sociais 'à distância' com contextualidades locais [...]" (GIDDENS, 2002, p. 27). Para Giddens (2001, p. 73), a globalização não é um fenômeno apenas econômico, “é social, política e cultural”.

\section{Zygmunt Bauman e a "modernidade líquida"}


Bauman ao investigar o espírito inquieto da modernidade, diagnosticou que a vida contemporânea se apresenta aos indivíduos de uma determinada forma que desestimula o aprofundamento nas relações interpessoais, não há espaço para laços sólidos e duradouros. Os indivíduos, na vida cotidiana, interiorizaram a perspectiva do "eternamente novo" e por isso não aprofundam os seus relacionamentos, "os sólidos laços sociais e afetivos são liquefeitos, fragilizados, descompromissados" (SILVA, 2010, p. 20).

Freud, em sua obra o Mal-estar na civilização, defende a tese de que a civilização ocidental castra os impulsos dos homens diminuindo a sua liberdade individual para obter, em contrapartida, a segurança proporcionada pela vida coletiva, ou seja, há uma troca, um sacrifício da liberdade individual para desfrutar da segurança ofertada pela vida em conjunto. Analisando a contemporaneidade, Bauman afirma que, se Freud produzisse sua obra nos contornos da atualidade, provavelmente iria continuar defendendo a ideia que a cultura castra os impulsos, mas inverteria seu diagnóstico da troca da liberdade pela segurança. Essa ideia esta expressa na seguinte passagem, “[...] os problemas e desgostos humanos mais comuns atualmente são, como antes, produto de trocas, mas agora é a segurança que se sacrifica diariamente no altar da liberdade individual em expansão". (BAUMAN, 2000, p. 24). No atual momento histórico, o mal estar não se encontra na falta da liberdade individual e sim na inexistência da segurança, “[...] o mundo contemporâneo é um recipiente cheio até a borda de medo e frustração à solta que buscam desesperadamente válvulas de escape.” (BAUMAN, 2000 , p. 22). De acordo com Fridman "atualmente os ganhos e as perdas mudaram de lugar" (FRIDMAN, 1999, p. 167). Para Bauman a busca pelo prazer se dá pelo consumo, o indivíduo está sempre habilitado a se transformar, a abandonar as velhas práticas e a consumir novas mercadorias e serviços, que são sempre vendidas ao seu consumidor não só como um produto ou serviço, mas como um "estilo de vida". Os indivíduos vivem "uma vida subordinada à tarefa de construir a identidade" (BAUMAN, 1998, p.37). Nesse sentido, tornam-se "colecionadores de experiências", sempre em "busca de novas e ainda não apreciadas experiências" (BAUMAN, 1998, p.22). O mercado se organiza no sentido de atrair o consumidor, sempre o seduzindo "pelas propostas de aventura", alimentando vigorosamente a insatisfação, impedindo a "ossificação de quaisquer hábitos adquiridos", incentivando a busca por novas experiências (BAUMAN, 1998). A experiência mais intensa é sempre a próxima.

A condição para a adaptação da identidade, segundo Bauman (1998, p. 36 e 37), é a arte de esquecer, "[...] a própria memória é como uma fita de vídeo, sempre pronta a ser apagada a fim de receber novas imagens." Construir uma identidade em longo prazo, de maneira, planejada, articulada, sólida, clara, duradoura e viver a vida voltada para essa 
identidade, no atual estágio da modernidade é uma tarefa quase impossível (BAUMAN, 1998).

Bauman observa que na atualidade há uma "segurança incerta" no universo do trabalho devido ao alto índice de rotatividade. Observamos um quadro "diametralmente oposto" ao de algumas décadas atrás, em que as ocupações se caracterizavam por ser do tipo "40/40" (quarenta horas semanais por quarenta anos), uma estabilidade que era assegurada pelos sindicatos e pelas políticas de bem estar social (welfare state). De maneira perspicaz, Bauman observa que “empregos vitalícios já não existem mais” (BAUMAN, 1998, p. 50). “O companheirismo no trabalho carece de tempo para se consolidar" (FRIDMAN, 2014, p. 263), a alta rotatividade nos postos de trabalho, o fim da estabilidade associado à ameaça permanente de desemprego não "favorece a criação de laços fortes entre indivíduos" (FRIDMAN, 2014, p. 263).

Fridman, em seus escritos sobre Bauman, ressalta que o diagnóstico deste sociólogo converge com as pesquisas realizadas por Richard Sennett sobre o esfriamento das relações sociais. Para Sennett, na "reorganização produtiva do capitalismo da especialização flexível" (FRIDMAN, 2014, p. 262), os trabalhadores são realocados com frequência, em curto espaço de tempo, são obrigados a se adaptarem com rapidez às modificações e às novas condições de trabalho. O trabalhador deve ser menos dependente possível do outro, pois a dependência para a realização de tarefas é visto como algo vergonhoso. Segundo Sennett, vivemos na era dos "laços fracos" (SENNET, 2009). A falta de solidariedade no trabalho se derrama para outras esferas da vida.

O Estado já não assume mais a tarefa política de assegurar os direitos dos trabalhadores e a reprodução da ordem sistêmica ficou a cargo do mercado desregulamentado e cada vez mais flexível e fragmentado, agora "a tarefa de lidar com os riscos coletivamente produzidos foi privatizada" (BAUMAN, 1998, p. 52). No mundo da fragilidade da "ordem" impera as incertezas, instabilidade, insegurança, medos e frustrações, os indivíduos estão sujeitados à própria sorte e são metralhados por uma infinidade de profissionais "conselheiros" ofertados como mercadorias em prateleiras de redes de supermercados, para tais concorrem: nutricionistas, paisagistas, personal trainers, personal style, personal shopper, decoradores de interiores, esteticistas, sexólogos, educadores financeiros, economistas, pedagogos, psicólogos, religiosos, comunicólogos, estilistas, apresentadores de programas de rádio e televisão etc., todos possuem um conselho na medida certa para cada pessoa em momentos específicos, caso não agradem o gosto ou as necessidades do cliente, são descartados e substituídos por outro "conselheiro". 
Outro aspecto interessante a ser observado é o mercado editorial que atualmente vivencia uma explosão de venda de livros de autoajuda. São escritores que se propõem a dar um suporte emocional ou "espiritual" para encarar a dinâmica da vida, seja no trabalho, nos negócios, na política, nos relacionamentos ou na educação dos filhos. São eles que dizem o que você deve fazer, como fazer, quando e onde. São livros que fornecem dicas sobre questões práticas de como alcançar algo que deseja. "A literatura de autoajuda caracteriza-se textualmente pelo discurso prescritivo, tendo como principal objetivo propor regras de conduta e fornecer conselhos [...]" (RÜDIGER, 2010, p. 22).

Uma pesquisa qualitativa, realizada pelo Ateliê de Pesquisa Organizacional (2006), sobre o impacto dos livros de autoajuda profissional em ambientes de trabalho revelou que a maioria dos profissionais entrevistados entende que os livros de autoajuda fornecem "dicas para melhorar", "abre caminhos", "orienta”, "dá segurança", "direciona, motiva", "aconselha", entre outros. Os mesmos entrevistados comparam essa literatura com figuras de autoridade como "pai", "professor", "padre", "autoridade", "chefe" e "milagreiro", ou seja, pessoas, que tradicionalmente se encontram na posição de "aconselhar". Os resultados apresentados por esta pesquisa confirmam a tese de Rüdiger mencionada acima. A pesquisa revela também que, entre os entrevistados, “o livro de autoajuda tem a função de 'humanizar' o dia a dia, muitas vezes, desumano", também serve de instrumento de mediação entre pessoas, um mediador mudo. Rüdiger faz a seguinte reflexão sobre o fenômeno da literatura de autoajuda:

O fenômeno refere-se, em resumo, ao conjunto textualmente mediado de práticas através das quais as pessoas procuram descobrir, cultivar e empregar seus supostos recursos interiores e transformar sua subjetividade, visando conseguir uma determinada posição individual supra ou intramundana. (RÜDIGER, 2010, p. 8)

Os livros de autoajuda sempre apresentam pessoas com histórias recheadas de situações difíceis e conflituosas, mas que superaram as dificuldades com muita "garra", "vontade", "trabalho", "perseverança","sacrifício" e "determinação", são personagens que servem de exemplo e inspiração para seus leitores, com "histórias de superação", para que estes adotem em seu cotidiano uma determinada conduta de vida capaz de intervir sobre a realidade e transformá-la a seu favor. No mundo "desengajado", os profissionais especializados em aconselhar juntamente com a literatura de autoajuda, apresentam um conjunto de orientações para se alcançar à "sagacidade e a força muscular individual", no "esforço diário pela sobrevivência e aperfeiçoamento" (BAUMAN, 1998, p. 54). Os 
"conselheiros" e os livros de autoajuda, se convertem em recursos para suportar as dores produzidas por uma sociedade que introduz nos indivíduos a sensação permanente de incerteza.

$\mathrm{Na}$ atualidade, o apelo neoliberal acionou uma série de dispositivos que engendraram um conjunto de estratégias de mercado que transformaram o mundo do trabalho em um palco de luta generalizada pela sobrevivência, as empresas criaram a cultura da "sensação de incerteza paralisante", tendo como último recurso "[...] a permanente ameaça de demissão em todos os níveis da hierarquia - o que significa a perda do meio de subsistência, dos títulos sociais, do lugar na sociedade e da dignidade humana que os acompanha." (BAUMAN, 2000, p. 37).

Um ponto fundamental e de grande relevância no pensamento do sociólogo polonês, que permite compreender a dinâmica da vida moderna na atualidade, são as formas de reprodução de capital e de produção do conhecimento. Bauman (2000, p.126) observa que, no "estágio hardware dos tempos modernos", o capital era "localmente orientado", ou seja, "era forçado a arraigar-se, por bem ou por mal". "O capital e o saber foram ambos se emancipando de seu confinamento local" (BAUMAN, 2000, p.127). No atual momento, estão ocupando o "ciberespaço" na medida em que gradualmente desocupa o "espaço geográfico". A cada instante "o poder do capital perde cada vez mais sua materialidade, torna-se mais e mais “irreal”" (BAUMAN, 2000, p. 127). A "descorporificação" na era do "software" permite o capital ser "extraterritorial”, "o capital pode viajar rápido e leve, e sua leveza e mobilidade se tornam as fontes mais importantes de incerteza para todo o resto" (BAUMAN, 2000, p.141).

O capital é flexível e móvel, se movimenta na velocidade do "sinal eletrônico", bilhões de dólares ou euros são deslocados de um lado para o outro em fração de segundos, a maleabilidade do capital permite a realização de grandes jogadas monetárias. As forças econômicas vão se emancipando a cada minuto das instituições políticas. O capital possui o ritmo de um corredor velocista e o fôlego de um corredor maratonista, ou seja, percorre uma longa jornada em alta velocidade com fôlego suficiente para não parar no meio do percurso. As instituições políticas, por sua vez, perdem cada vez mais poder e autonomia e a sua capacidade de apreender, refletir e atuar sobre a realidade ao possuírem ritmo retardado em relação ao capital. A política, então, possui o ritmo de um corredor maratonista e o fôlego de um corredor velocista, ou seja, percorre um longo caminho em baixa velocidade e com fôlego insuficiente para terminar todo o percurso. Essa combinação deixa a política exaurida e debilitada para prosseguir na corrida. Em um artigo publicado no jornal La Republica, 
Bauman (2011) afirma que “[...] o que está acontecendo hoje é a indubitável separação, uma perspectiva de divórcio, entre poder e política.”

\section{Considerações finais}

Os dois autores, Giddens e Bauman, são reconhecidos academicamente pela elaboração e difusão de seus arcabouços teóricos no que diz respeito às discussões em torno da modernidade e suas peculiares instituições. Para Giddens, a modernidade é um conjunto de práticas sociais, de estilo de vida, manifestadas a partir do século XII e que se tornaram mundialmente influentes. As forças que estão por trás da modernidade são a industrialização, o capitalismo, o militarismo e a vigilância. Segundo ele, atualmente vivemos um período de radicalização e universalização da modernidade (1991).

Sobre a modernidade, Bauman trabalha com a metáfora da liquefação, segundo a qual:

A modernidade 'sólida' era uma era de engajamento mútuo. A modernidade 'fluída' é a época do desengajamento, da fuga fácil e da perseguição inútil. Na modernidade 'líquida' mandam os mais escapadiços, os que são livres para se mover de modo imperceptível. (BAUMAN, 2001, p. 140).

A transformação do estado sólido para o liquido é a "grande transformação" que ocorreu na modernidade.

Em relação à modernidade, Giddens e Bauman divergem em alguns pontos. Para Giddens, a modernidade avançada (ou radicalizada) viabiliza a autonomia, o preenchimento da esfera pública por demandas de autorrealização. Na modernidade líquida, para Bauman, as dores produzidas coletivamente são equacionadas no âmbito da esfera privada em "utopias privatizadas" (FRIDMAN, 2014).

Segundo Fridmam, Giddens se revela um otimista "prudente" com relação ao "projeto reflexivo do eu”, para Bauman “[...] o 'projeto reflexivo do eu' ainda está longe de trazer calor para o esfriamento das formas de convívio humano." (FRIDMAN, 2014, p.270). As reflexões de Bauman parecem convergir com as do antropólogo Maurice Godelier (2001, p. 317), quando este dizia que "nossa sociedade só vive e prospera [...] ao preço de um déficit de solidariedade."

\section{REFERÊNCIAS}

BAUMAN, Z. Podemos mudar o mundo imitando as borboletas. La Republica, São Leopoldo, 14 nov. 2011. Disponível em: <http://www.ihu.unisinos.br/noticias/502856- 
podemos-mudar-o-mundo-imitando-as-borboletas-artigo-de-zygmunt-bauman>. Acesso em: 29 jun. 2015.

BAUMAN, Z. Modernidade líquida. Rio de Janeiro: Zahar, 2001.

BAUMAN, Z. Em busca da política. Rio de Janeiro: Zahar, 2000.

BAUMAN, Z. O mal estar na pós-modernidade. Rio de Janeiro: Zahar, 1998.

BERMAN, M. Tudo o que é sólido se desmancha no ar: a aventura da modernidade. São Paulo: Companhia das Letras, 1986.

FOUCAULT, M. Iluminismo e crítica. Roma: Donzelli, 1999.

FRIDMAN, L. C. Próximos ou separados? ideias de Giddens e Bauman sobre as motivações para a política. Lua Nova: Revista de Cultura e Política, São Paulo, n. 92, p.241-271, 2014. Disponível em: <http://www.scielo.br/scielo.php?script=sci_arttext\&pid=S010264452014000200009\&lng=pt\&nrm=iso>. Acesso em: 21 jun. 2015.

FRIDMAN, L. C. Trabalho, especialização flexível e reflexividade desanimada. In: ENCONTRO ANUAL DA ANPOCS, 24., 2000, Petrópolis. Anais... Petrópolis: Anpocs, 2000.

FRIDMAN, L. C. Vertigens pós-modernas (Giddens, Touraine, Bauman). Lua Nova: Revista de Cultura e Política, São Paulo, n.47, p.157-251, ago. 1999. Disponível em: <http://www.scielo.br/pdf/ln/n47/a09n47.pdf>. Acesso em: 22 jun. 2015.

GIDDENS, A. Modernidade e identidade. Rio de Janeiro: Zahar, 2002.

GIDDENS, A. A terceira via e seus críticos. Rio de Janeiro: Record, 2001.

GIDDENS, A. As consequências da modernidade. São Paulo: UNESP, 1991.

GODELIER, M. O enigma do Don. Rio de Janeiro: Civilização Brasileira, 2001.

GOLDMAN, W. Prefácio à edição brasileira. In: GOLDMAN, W. Mulher, Estado e revolução. São Paulo: Boitempo: Iskra, 2014. p.09-14.

GOMES, I. M.; ALMEIDA, F. Q. de.; VAZ, A. F. Sobre corpo, reflexidade e poder: um diálogo entre Anthony Giddens e Michel Foucault. Política \& Sociedade, Santa Catarina, v. 8, n. 15, p. 299-319, 2009. Disponível em:

<https://periodicos.ufsc.br/index.php/politica/article/viewFile/11804/11047>. Acesso em: 05 fev. 2017.

HARVEY, D. O tempo e o espaço no projeto do iluminismo. In: HARVEY, D. Condição pós-moderna: uma pesquisa sobre as origens da mudança cultural. 7.ed. São Paulo: Loyola, 1989. p.219-35.

LIVROS de auto ajuda profissional. Ateliê de Pesquisa Organizacional, set. 2006. Disponível em: <http://www.ateliedepesquisa.com.br/wp- 
content/UPLOADS/2014/04/resultados_auto_ajuda.pdf>. Acesso em: 21/06/2015, às 02h49min.

MARX, K.; ENGELS, F. Manifesto do partido comunista. São Paulo: Expressão Popular, 2010.

RÜDIGER, F. Literatura de autoajuda e individualismo. Porto Alegre: Gattopardo, 2010.

SENNET, R. Corrosão do caráter: consequências pessoais do trabalho no novo capitalismo. Rio de Janeiro: Record, 2009.

SILVA, Q. M. L. G. da. A estética da desintegração: fragmentos da pós-modernidade em Waking Life. 2010. Trabalho de Conclusão de Curso (Graduação em Comunicação Social) Universidade do Estado do Rio de Janeiro, Rio de Janeiro, 2010.

\section{Como referenciar este artigo}

RIBEIRO, Wallace Cabral. Giddens e Bauman: as configurações institucionais na contemporaneidade. Rev. Sem Aspas, Araraquara, v.6, n.1, p. 13-25, jan./jun. 2017. e-ISSN $2358-4238$.

Submetido em: 15/04/2017

Aprovado em: 15/06/2017 